\title{
Colour modification of poplar wood by steaming for brown colour
}

\author{
Endre Antal Banadics ${ }^{1} \cdot$ Laszlo Tolvaj $^{1}$
}

Received: 13 May 2018 / Published online: 12 March 2019

(c) The Author(s) 2019

\begin{abstract}
The colour change of poplar was evaluated after exposure to a wide range of steaming parameters $\left(90-110{ }^{\circ} \mathrm{C}, 1-20\right.$ days $)$ for getting brown colour for indoor applications. The generated brown colour was homogeneous throughout the whole cross section. The colour saturation can be doubled by steaming. Steaming increased both redness and yellowness values and reduced the lightness. The initial redness value was multiplied 4.5 times.
\end{abstract}

\section{Introduction}

During steaming, the structure and components of natural wood material are affected by heat followed by physical and chemical transformation of wood components such as hemicelluloses and extractives. Poplar specimens were steamed at different temperatures to observe the combined effect of heat and moisture on the wood colour. Poplar was chosen because there have not been any steaming investigations at low temperature on poplar materials before. The intention was to develop graphical representations for the visualization of steaming time/temperature and colour parameter relations. Such diagrams may aid in the selection of appropriate steaming parameters to bring about desired colour hues and darkness of poplar wood.

\section{Materials and methods}

Dried poplar timber (Populus $\times$ euramericana $c v$. pannonia) was used for sample preparation, with sample dimensions of $30 \times 25 \times 160 \mathrm{~mm}^{3}(\mathrm{~W} \times \mathrm{H} \times \mathrm{L})$. The initial moisture content of the samples was between $8-12 \%$. Samples were prepared using both sapwood and heartwood separately. Steaming was carried out in an autoclave, which was able to keep the inner pressure. The chosen steaming temperatures were 90, 100 and $110^{\circ} \mathrm{C}$. The total steaming time was 20 days. The dry steamed samples were cut longitudinally in the middle and

Endre Antal Banadics

banadics.endre.antal@phd.uni-sopron.hu

1 Institute of Physics and Electrotechnics, University of Sopron, Bajcsy-Zs. str. 4., Sopron, Hungary the colour measurements were taken on the freshly formed surface. The colour coordinates were measured by a colorimeter KONICA-MINOLTA 2000d. The light source was D65 illuminant, and a $10^{\circ}$ standard observer with a testwindow diameter of $8 \mathrm{~mm}$ was applied.

\section{Results and discussion}

The original colour of poplar is greyish white and characterless. Visual observation showed that the colour turned to a much more pleasant brown compared to the initial colour. The lightness decreased for all types of treatments and the colour hue changed towards brown tone. The colour difference of earlywood and latewood became apparent, and the wood texture became more visible. The colour of steamed wood was homogeneous throughout the whole cross section.

The objective colour measurement gives a more detailed information on the colour alteration than visual observation. Figure 1 shows the lightness change due to the thermal treatment for all temperature settings. The value of lightness was significantly reduced for all cases. The initial colour of heartwood was darker (3 units) than that of sapwood. The lightness difference remained small between sapwood and heartwood during the first 5 days of steaming. Then, the curves drifted apart over time. The only exception was $90{ }^{\circ} \mathrm{C}$, where the lightness values of sapwood and heartwood have changed almost equally during the steaming period. The greatest lightness decrease was 28 units generated by 20-day steaming at $100{ }^{\circ} \mathrm{C}$. The results strengthened the authors' hypothesis that steaming is a proper method to produce dark colour for poplar wood. Three different processes generated the lightness change. The coloured degradation 


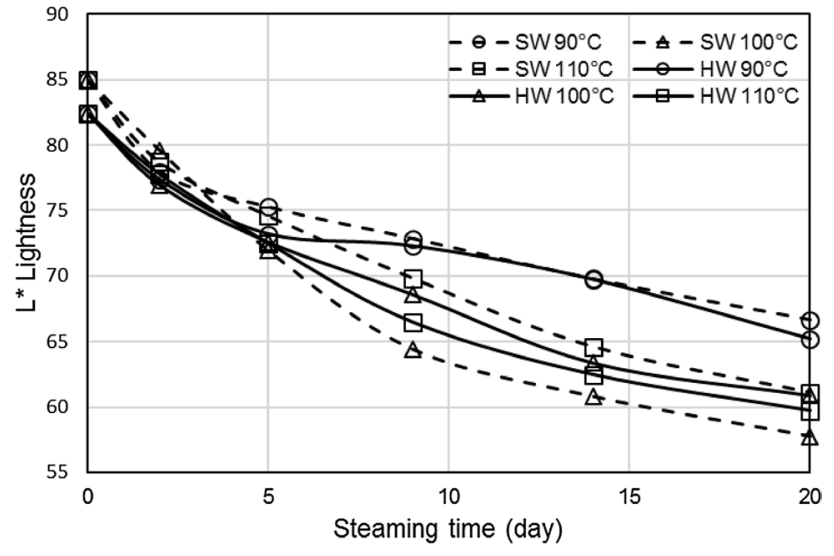

Fig. 1 Changes of lightness as a function of steaming parameters

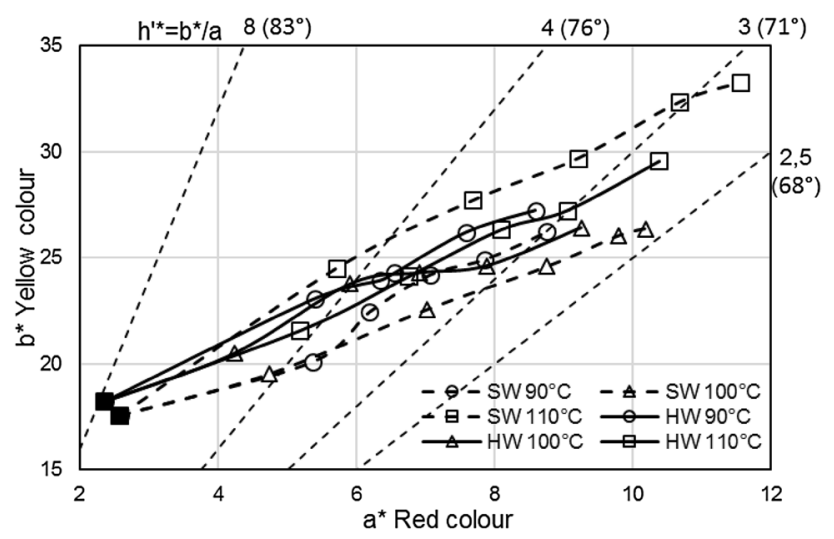

Fig. 2 Chromaticity change of poplar as a function of steaming parameters

products of extractives and hemicelluloses reduce the value of lightness, whereas the leaching effect of high temperature steam increased the value of lightness. These processes are temperature-dependent in different ways, which is why the order of the curves does not follow the temperature steps in the case of sapwood but in the case of heartwood. Lightness, however, is not a proper parameter to track ongoing chemical changes. Chromaticity coordinates $\left(a^{*}\right.$ and $\left.b^{*}\right)$ make much more chemical sense than the lightness, although the latter is an important parameter from an industrial point of view.

Figure 2 shows the change of redness $\left(a^{*}\right)$, yellowness $\left(b^{*}\right)$, hue $\left(h^{*}\right)$ and indirectly the saturation. Solid symbols represent the initial hue values while empty symbols denote the same relations as a function of increasing treatment time from left to right. The extractives contribute mostly to temperature-induced colour changes of wood by formation of various conjugated double bonds, carbonyl functionalities and quinoid structures (Liu et al. 2017). The initial redness of the specimens was low, 2.36 and 2.58 for heartwood and sapwood, respectively. This is because the extractive content of poplar is low, i.e., the extractives were not the main generators of redness increase. The redness value increased continuously for all specimens with elapsed steaming time. This increase was intensive during the first 5 days of steaming, where the initial values were multiplied by $2.5-3$. This change was followed by moderate redness increase. In contrast, black locust having high extractive content showed intensive redness increase during the first 2 days of steaming at temperatures above $90{ }^{\circ} \mathrm{C}$. After reaching the maximum, the redness value decreased continuously. The reason is that the newly generated chromophore degradation products of extractive are not stable enough. High temperature steam may degrade them, causing a significant reduction in the red colour value (Tolvaj et al. 2010; Csanady et al. 2015). In the present case, the continuous redness increase demonstrates clearly that the degradation products of hemicelluloses play a dominant role in redness change of poplar during steaming. The $\mathrm{a}^{*}$ values of sapwood and heartwood were close to each other during steaming at $90{ }^{\circ} \mathrm{C}$. From an industrial aspect, steaming at $110{ }^{\circ} \mathrm{C}$ is the most effective method to generate brown coloured poplar timber. The highest redness value, which can be generated by 20 days steaming at $110^{\circ} \mathrm{C}$, is 11.55 units, which is 4.5 times higher than the initial redness value. By choosing the proper steaming time, the desired colour can be generated.

Figure 2 represents the yellowness change caused by steaming at 90,100 and $110^{\circ} \mathrm{C}$. The increase in the yellow colour coordinate $\left(b^{*}\right)$ was similar to the $a^{*}$ value increase. The yellowness change was, however, less temperaturedependent than the redness change. At $90{ }^{\circ} \mathrm{C}$ and $100{ }^{\circ} \mathrm{C}$, the samples showed a similar behaviour; the curves of sapwood and heartwood were close to each other regardless of the steaming temperatures. The treatment at $110{ }^{\circ} \mathrm{C}$ generated significant yellowness increase for sapwood and small increase for heartwood, compared to the lower temperatures applied. The most intensive increase occurred during the first 5 days of steaming at $110{ }^{\circ} \mathrm{C}$. The initial yellowness values were multiplied by 1.3 and 1.57 for heartwood and sapwood, respectively, during this period. This change was followed by moderate yellowness increase. The highest yellowness value generated by 20 days of steaming at $110{ }^{\circ} \mathrm{C}$ is 33.25 units, which is 1.9 times higher than the initial yellowness value. In contrast, the highest redness value was 4.5 times greater than the initial value, showing that the redness change was much more dominant than the yellowness change. The steaming at $110{ }^{\circ} \mathrm{C}$ produced greater redness increase for sapwood than for heartwood generating visible colour difference. The possible colour modification effects of extractives were discussed in a previous paper (Nemeth et al. 2016): "The condensation of the tannin molecules and the oxidation of the hydroxyl groups in flavonol molecules make up the potential reason for the formation of new colour substances during heat treatment. The elimination of 
the dioxane extractives can effectively reduce the extent of thermally induced discoloration".

The colour hue is represented by the polar angle on $\mathrm{a}^{*}-\mathrm{b}^{*}$ plane. The colour of wood is located between $0^{\circ}$ (red) and $90^{\circ}$ (yellow). European wood species are more yellow than red. These hue values are between $56^{\circ}$ and $83^{\circ}$. The highest value belongs to the light wood species (spruce, poplar) and natural black locust, and the lowest value to the steamed black locust (chocolate brown). The hue angle of poplar decreased continuously during steaming. The hue angle decrease is hardly temperature- nor sapwood-heartwood dependent. The distance between the highest and lowest angle is $4.6^{\circ}$ after 9 days of steaming. This distance was slightly reduced (one unit) during the next 11 days of steaming. The hue angle around $70^{\circ}$ represents an attractive light brown colour.

Colour saturation refers to the intensity of colour in an image. The increasing saturation shows how a pale hue turns to pure. The steaming intensifies the saturation of poplar at all investigated temperatures. The saturation increase was similar for most treatments. The only exception was the $110^{\circ} \mathrm{C}$ for sapwood. In this case, the brown colour of steamed samples became more intensive than in other cases. The highest saturation value is twice as high as the initial value.

\section{Conclusion}

Poplar specimens were steamed to generate attractive brown colour for indoor applications. The steaming time varied between 90 and $110{ }^{\circ} \mathrm{C}$. The colour change of both sapwood and heartwood was evaluated. The results showed that steaming is a proper method to produce brown colour for poplar wood. The colour saturation could be doubled by steaming. The colour of steamed wood was homogeneous throughout the whole cross section. Steaming generated much greater redness increase than yellowness increase. Steaming of poplar can 4.5 times multiply the initial redness value and 1.9 times the yellowness value.

Acknowledgements Open access funding provided by University of Sopron (SOE). This research was sponsored by the OTKA K116216 "Complex analysis of the physico-mechanical and surfacephysical properties of wood with low density" project and TÉT12-MA-1-2016-0086 "Development of extractive-transport based hydrothermal treatment technology for the color modification and homogenization of selected Hungarian and Japanese wood species" project. The financial supports are gratefully acknowledged.

Open Access This article is distributed under the terms of the Creative Commons Attribution 4.0 International License (http://creativeco mmons.org/licenses/by/4.0/), which permits unrestricted use, distribution, and reproduction in any medium, provided you give appropriate credit to the original author(s) and the source, provide a link to the Creative Commons license, and indicate if changes were made.

\section{References}

Csanady E, Magoss E, Tolvaj L (2015) Quality of machined wood surfaces. Springer International Publishing, Berlin, pp 81 https:// doi.org/10.1007/978-3-319-22419-0

Nemeth R, Hill CAS, Takats P, Tolvaj L (2016) Chemical changes of wood during steaming measured by IR spectroscopy. Wood Mat Sci Eng 11(2):95-101

Tolvaj L, Molnár S, Németh R, Varga D (2010) Colour modification of black locust depending on the steaming parameters. Wood Res 55(2):81-88

Liu XY, Timar MC, Varodi AM, Sawyer G (2017) An investigation of accelerated temperature-induced ageing of four wood species: colour and FTIR. Wood Sci Technol 51:357-378

Publisher's Note Springer Nature remains neutral with regard to jurisdictional claims in published maps and institutional affiliations. 